\title{
Attention Deficit Hyperactivity Disorder (ADHD) and Associated Factors Among First-Year Elementary School Students
}

\author{
Hai Huu Hoang $\mathbb{D}^{1, *}$ \\ Anh Thi Ngoc Tran $\mathbb{D D}^{2, *}$ \\ Van Hung Nguyen $\mathbb{1}^{3}$ \\ Thi Thanh Binh Nguyen (iD ${ }^{4}$ \\ Thi Anh Phuong Nguyen ${ }^{5}$ \\ Dinh Duong Le $\mathbb{I D}^{3}$ \\ Alfred Jatho $\mathbb{D D}^{6}$ \\ David Onchonga ${ }^{7}$ \\ Tuyen Van Duong (D) 8 \\ Minh Tu Nguyen (D) ${ }^{9}$ \\ Binh Thang Tran (1D ${ }^{3}$
}

'Student's Affairs Office, Hue University of Medicine and Pharmacy, Hue University,

Hue City, Vietnam; ${ }^{2}$ Institute of

Gastroenterology and Hepatology, Hanoi,

Vietnam; ${ }^{3}$ Faculty of Public Health, Hue

University of Medicine and Pharmacy, Hue

University, Hue City, Vietnam;

${ }^{4}$ Department of Paediatrics, Hue University of Medicine and Pharmacy, Hue University, Hue City, Vietnam; ${ }^{5}$ Faculty of Nursing.

Hue University of Medicine and Pharmacy,

Hue University, Hue City, Vietnam;

${ }^{6}$ Department of Cancer Control and

Population Health, Graduate School of

Cancer Science and Policy, National Cancer

Center, Goyang, Republic of Korea;

${ }^{7}$ Doctoral School of Health Sciences,

University of Pécs, Pécs, Hungary; ${ }^{8}$ School

of Nutrition and Health Sciences, Taipei

Medical University, Taipei, I I0-3I, Taiwan;

'Undergraduate Training Office, Hue

University of Medicine and Pharmacy, Hue

University, Hue City, Vietnam

*These authors contributed equally to this work

Correspondence: Binh Thang Tran

Faculty of Public Health, Hue University

of Medicine and Pharmacy, Hue

University, 06 Ngo Quyen Street, Hue

City, Thua Thien Hue, Vietnam

Email tranbinhthang@hueuni.edu.vn
Purpose: Attention deficit hyperactivity disorder (ADHD) is a mental health disorder commonly in children. This study aimed to examine the prevalence of ADHD and risk factors among first-year pupils in Vietnam's urban city.

Patients and Methods: A cross-sectional study was conducted in four randomly selected primary schools. Information on 525 pupils in grade 1 (ages 6 to 7 years) was collected from 525 parents/caregivers and 28 teachers. We used the Vanderbilt Assessment Scales with two separate versions for parents and teachers to screen children with ADHD symptoms.

Results: Among the total of 525 pupils, 24 (4.6\%) were found to have ADHD symptom types (boy: 6.5\%; girl: 2.1\%). The combined ADHD type accounted for the highest proportion of $3.4 \%$, followed by predominantly inattentive and predominantly hyperactivity type. ADHD prevalence rated by teachers was higher than those rated by parents. High agreement between parents and teachers was reported $(\kappa>0.6)$. The risk of ADHD increased in male participants $(\mathrm{aOR}=4.90,95 \%$ CI $1.51-15.85)$, those having a first-degree relative with ADHD $(\mathrm{aOR}=85.2,95 \%$ CI 1.66-4371.8), in-utero exposure to tobacco smoke $(\mathrm{aOR}=4.78$, 95\% CI 1.31-17.44), and prenatal alcohol drinking (aOR=8.87, 95\% CI 2.29-34.42).

Conclusion: These findings suggest the importance of ADHD screening for pupils attending elementary schools, particularly those with a family history of ADHD. Public health programs should reduce prenatal exposure to the potential risk factors of ADHD (smoking and alcohol consumption).

Keywords: attention deficit hyperactivity disorder, ADHD, school health, children, risk factors, Vietnam

\section{Introduction}

Attention deficit hyperactivity disorder (ADHD) is a mental disorder that usually manifests in childhood characterized by hyperactivity, impulsivity, and inattention. ${ }^{1}$ According to the Diagnostic and Statistical Manual of Mental Disorder (DSM), ADHD is classified into three subtypes following its main symptom, namely predominantly inattentive (ADHD-I), predominantly hyperactivity/impulsivity (ADHD-HI), and combined (ADHD-C) type. ${ }^{1}$ Individuals diagnosed with ADHD would be at a higher risk of comorbid psychiatric disorders, including depression, anxiety disorder, ${ }^{2}$ and face many obstructions in social connections, vocational outcomes, school performance, earlier educational termination as consequences of impulsive behaviours, restlessness, and lack of focus, ${ }^{1}$ even resulting in reduced quality of life and premature death. ${ }^{1}$ ADHD patients and their families also suffer 
from unavoidable burdens, specifically adverse finance for treatment and education, combined with incurring mental pressure. $^{3}$ The estimated ADHD prevalence varies widely across countries, population settings, and diagnostic criteria. A previously pooled analysis of 102 original studies has illustrated that the adult ADHD prevalence rate was 26.2\% (95\% CI: 22.7-29.6). ${ }^{4}$ Also, ADHD has presented a rising trend in the United States and the world population. ${ }^{5}$

The onset of ADHD is commonly at early-stage, in school-age groups ${ }^{1}$ with an estimated prevalence between 4 and $12 \%$ worldwide. $^{6}$ Children aged 10 years and younger were found to be four times higher at risk of ADHD in a previous study. ${ }^{7}$ Noticeably, an earlier study has proved that $60-80 \%$ of childhood ADHD cases were not diagnosed and had mental disorders in adult life, such as autism, anxiety disorder, and unemployment, drug, and alcohol abuse in the next life stages specific to adolescence and adulthood. ${ }^{8}$ Biological mechanisms that lead to ADHD syndromes in children remain mostly unknown. ${ }^{1}$ No single risk factors but highly heritable and multifactorial factors driven by gene-environmental interactions contribute to this disorder. ${ }^{1,9}$

Furthermore, prenatal and perinatal factors have been identified as risks, including childhood adverse experience, maternal pregnancy risk exposures and complications, but defined causes have not been largely discovered. ${ }^{1}$ The ADHD diagnosis can be performed on children as young as four years old, and it might be more challenging for adolescents. $^{10,11}$ Therefore, evaluations for ADHD for especially preschool-aged and primary school-aged children, are recommended and of the utmost importance to improve the efficiency of future treatments and interventions. $^{12}$

Despite being one of the most common childhood disorders, ${ }^{1}$ screening and proper management for ADHD syndromes has not been noted in health programs that were directed in primary schools in Vietnam since $2006,{ }^{13}$ this partly due to a lack of data and analysis as well as awareness on ADHD among school children. To our best knowledge, in Vietnam, only one report conducted in 2009 indicated that the prevalence of ADHD was $7.7 \%$ and doubled among children living in the urban than rural areas; however, associated factors to ADHD have been unexplored. ${ }^{14}$ In the context of increasing urbanization in Vietnam that might subsequently increase the risk of ADHD syndrome due to gene-environmental interaction, ${ }^{15}$ children's health-related to ADHD needs more consideration. Like other developing countries, Vietnamese children are getting more attention and investments in terms of education and health care than their predecessors; however, evidence of mental health problems/demands, in particular ADHD prevalence and related factors to suggest appropriate health managements considered to be feasible for primary schools and families have been lacking.

Therefore, in this study, we aimed to examine the prevalence of ADHD and determine factors correlated with ADHD syndromes among 6-to-7-year-old children at schools in Hue city of Vietnam.

\section{Patients and Methods Study Population}

A cross-sectional study was conducted in the first-grade elementary students from March to May 2019 in four randomly selected primary schools in Hue city located in the central of Vietnam.

\section{Sample Size and Sampling}

Sample size calculation was performed by using the formula: $n=Z_{1-\alpha / 2}^{2} x \frac{p(1-p)}{d^{2}} x D$. Based on a previous study carried out in Vietnam, it is estimated that ADHD prevalence among primary pupils (p) is $7.7 \% .{ }^{14}$ We set the significance level $(\alpha)$ at 0.05 , error margin (d) at 0.05 , and the design coefficient (D) equals 4 . We computed the needed sample size is 492 . We assumed the level of nonresponse rate of 5\%. Our final sample size was 525 pupils, and age ranges from 6 to 7 years.

We used a two-stage random sampling approach: First, to selecting sampled schools as representative of the geography and socioeconomic characteristics of each area, we separated Hue city into two areas: the north area with 19 primary schools and the south area with 15 primary schools. Four schools were randomly selected from the 34 schools, with two schools for each area. Second, a list of total pupils at 28 grade 1 classes of the selected schools was made. Then, 20-25 pupils in each class were randomly selected from the list. Eventually, 525 pupils in total were randomly selected $(135,141,97$, and 152 pupils in Phu Cat, Thuan Loc, Ngu Binh and Truong An school, respectively).

The invitation letters and informed consents were directly given to 28 teachers in of the 28 selected grade 1 classes and mothers/fathers/other guardians of the pupils to take part in the study. Finally, we collected information 
on the pupils from their 139 fathers, 331 mothers, 55 other caregivers, and 28 teachers.

\section{Theoretical Framework}

Given our interest in determining related factors to ADHD syndromes among children, we developed a theoretical framework that consists of 3 components (Figure 1) that enumerate factors previously described as possible related to ADHD syndromes among children collected from previous evidence. ${ }^{1,16-21}$ The components include children's sociodemographic background, adverse childhood experience, familial factors, adverse experiences during pregnancy.

\section{Data Collection Procedure}

All teachers and parents/guardians were directly interviewed by using two types of survey instruments for each subject. The interviews with teachers were carried out in the schools, while the interviews with parents were conducted at home. Each interview may take about 40 minutes. At the end of the interviewing day, the study supervisor checked all responses to the questionnaires.

\section{Measurement Instruments}

Both questionnaires for teachers and parents were divided into two parts. The first part includes questions about the sociodemographic information, personal characteristics of children, and the maternal factors for parents. The second part includes the National Institute for Children's Health Quality (NICHQ) Vanderbilt assessment scales with two separate versions for parents/caregivers and teachers to evaluate children with ADHD symptom types within the last six months and academic performance. ${ }^{22}$ The Vanderbilt assessment scales for teachers and parents/caregivers were translated into Vietnamese and culturally reviewed by psychologists, psychiatrists, and teachers before conducting pilot testing for language, setting, and interval time. We then revised inappropriate items and validated the questionnaires based on results of the pilot. The Cronbach's alpha value for the total score of the parents and teachers' version were 0.947 and 0.969 , respectively.

The scale for teachers consists of 43 items, including items 1-18 that assess for disorder symptoms scored based on the frequency: 0 . Never, 1. Occasionally, 2. Often and 3. Very often. Additional three items assessing academic performance and five items that assess classroom behavioural performance were asked. These items were scored on a 5-level Likert scale from 1) Excellent, 2) Above average, 3) Average, 4) Somewhat of a Problem and 5) Problematic. $^{22}$

The scale for parents/caregivers had 55 items, consisting of items $1-47$ assessing disorder symptoms rated based

\section{Children's sociodemographic background} -Sex

-Weight at birth

- Gestational age

Familial factor

- Family history of ADHD

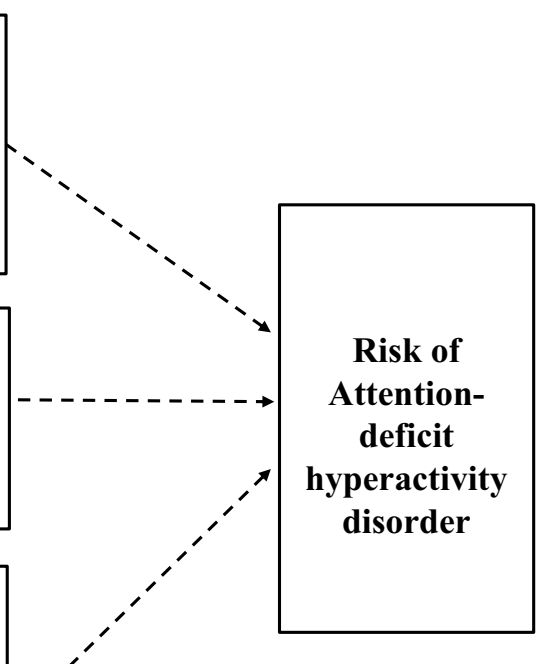

Adverse experience during pregnancy

-Mother's age at childbirth

-Previous miscarriage

-Maternal tobacco exposure

-Maternal alcohol drinking

Figure I The theoretical framework of related factors to ADHD. 
on the frequency: 0 . Never, 1. Occasionally, 2. Often and 3. Very often. Items 48-55 described the children's academic achievements and their relationships at school. Each item was assessed on a 5-level Likert scale from 1) Excellent, 2) Above average, 3) Average, 4) Somewhat of a problem, and 5) Problematic. ${ }^{22}$

According to DSM-5 classification as the gold standard for diagnosis of ADHD, ${ }^{23}$ ADHD was identified in children if only confirmed by both their parents/other guardians and teachers. Predominantly Inattentive type (ADHD-I) was defined when the score is 2 or 3 for 6 or more behaviours from questions $1-9$ in both scales and a 4 or 5 on any of the questions $36-43$ in teacher's scale and questions $48-55$ in parent's scale. Predominantly Hyperactive-Impulsive type (ADHD-HI) was defined if the score is 2 or 3 on 6 or more questions $10-18$ and a 4 or 5 on any of questions $36-43$ in teacher's scale and questions $48-55$ in parent's scale. A child is diagnosed with a combined type (ADHD-C) if they were scored as having two criteria of both ADHD-I and ADHD-HI. ${ }^{22}$

\section{Statistical Analysis}

Demographic characteristics of the pupils were summarized using numbers and frequencies. Chi-square tests was used to compare the differences of characteristics between pupils with ADHD and those with non-ADHD. Bivariate and multivariate logistic regression models were performed to determine the associated factors with ADHD among the pupils. All statistical significance level (P-value) was set at less than 0.05. All statistical analysis was performed using STATA version 14 (StataCorp, College Station, TX, USA).

\section{Ethical Statements}

The study was conducted in accordance with the Declaration of Helsinki and approved by the Ethics Committee for Biomedical Researches of Hue University of Medicine and Pharmacy (No: H2018/324, date of approval: 31/05/2018). The Board of Presidents of selected schools approved the study. Each school president was advised and agreed to conduct the study. Parents/teachers were given information about the study's reason and process as well as agreed to sign in an informed consent at the beginning of the interview. All study participants voluntarily participate in the study.

\section{Results}

Descriptive statistics on the pupils' sociodemographic characteristics and related maternal and family factors
Table I Characteristics of the First-Year Elementary Students

\begin{tabular}{|c|c|c|c|c|}
\hline Variables & $\begin{array}{l}\text { Total } \\
\text { n (\%) }\end{array}$ & $\begin{array}{c}\text { Non- } \\
\text { ADHD } \\
\text { n (\%) }\end{array}$ & $\begin{array}{c}\text { ADHD } \\
\text { n (\%) }\end{array}$ & $p$-value \\
\hline \multicolumn{5}{|l|}{ Sex } \\
\hline Girl & $236(45.0)$ & $231(46.2)$ & $5(20.8)$ & 0.015 \\
\hline Boy & $289(55.0)$ & 270 (53.9) & $19(79.1)$ & \\
\hline \multicolumn{5}{|l|}{ School location } \\
\hline North of city & $255(48.6)$ & $243(48.5)$ & $12(50.0)$ & 0.886 \\
\hline South of city & $270(5 I .4)$ & $258(5 \mid .5)$ & $12(50.0)$ & \\
\hline \multicolumn{5}{|l|}{$\begin{array}{l}\text { Weight at birth, } \\
\text { grams }\end{array}$} \\
\hline$<2500$ & $12(2.3)$ & II (2.2) & I (4.2) & 0.528 \\
\hline$\geq 2500$ & $513(97.7)$ & $490(97.8)$ & $23(95.8)$ & \\
\hline \multicolumn{5}{|l|}{$\begin{array}{l}\text { Gestational age at } \\
\text { birth, weeks }\end{array}$} \\
\hline$<37$ & 31 (5.9) & $26(5.2)$ & $5(20.8)$ & 0.001 \\
\hline$\geq 37$ & $494(94.1)$ & $475(94.8)$ & $19(79.2)$ & \\
\hline \multicolumn{5}{|l|}{$\begin{array}{l}\text { First-degree } \\
\text { relative history of } \\
\text { ADHD }\end{array}$} \\
\hline No & $522(99.4)$ & $500(99.8)$ & $22(91.7)$ & 0.000 \\
\hline Yes & $3(0.6)$ & I $(0.2)$ & $2(8.3)$ & \\
\hline \multicolumn{5}{|l|}{$\begin{array}{l}\text { Maternal age at } \\
\text { child's birth, years }\end{array}$} \\
\hline$\geq 35$ & $106(20.2)$ & $100(20.0)$ & $6(25)$ & 0.548 \\
\hline$<35$ & $419(79.8)$ & $40 I(80.0)$ & $18(75)$ & \\
\hline \multicolumn{5}{|l|}{$\begin{array}{l}\text { Previous } \\
\text { miscarriage }\end{array}$} \\
\hline No & $511(97.3)$ & $488(97.4)$ & $23(95.8)$ & 0.641 \\
\hline Yes & $14(2.7)$ & $13(2.6)$ & I (4.2) & \\
\hline \multicolumn{5}{|l|}{$\begin{array}{l}\text { Maternal smoking } \\
\text { or exposure } \\
\text { during pregnancy }\end{array}$} \\
\hline No & $215(41.0)$ & $212(42.3)$ & $3(12.5)$ & 0.004 \\
\hline Yes & $310(59.0)$ & $289(57.7)$ & $21(87.5)$ & \\
\hline \multicolumn{5}{|l|}{$\begin{array}{l}\text { Maternal alcohol } \\
\text { drinking during } \\
\text { pregnancy }\end{array}$} \\
\hline No & 507 (96.6) & $489(97.6)$ & $18(75.0)$ & 0.000 \\
\hline Yes & $18(3.4)$ & $12(2.4)$ & $6(25.0)$ & \\
\hline
\end{tabular}

Abbreviation: ADHA, attention deficit hyperactivity disorder.

are shown in Table 1. A sum of 525 parents/other caregivers and 28 teachers participated in the assessment of ADHD of pupils, given a participation rate of $100 \%$. Of the 525 pupils, $289(55 \%)$ were boys, only $12(2.3 \%)$ 
weighted at birth lower than 2500g, and 32 (5.9\%) had gestational age at birth of lower than 37 weeks. Out of a total, 3 pupils $(0.6 \%)$ had first-degree relatives in a family with ADHD and 14 mothers of the total pupils $(2.7 \%)$ had a history of prenatal miscarriage. Half of the pupils had prenatal passive exposure to tobacco smoke, and only $3.4 \%(n=18)$ had prenatal alcohol drinking.

$24(4.6 \%)$ pupils found to have ADHD symptoms types using the Vanderbilt Assessment scales (Table 2). In particular, the combined ADHD (ADHD-C) type accounted for the highest proportion of 3.4\% (18/525); the ADHD-I and ADHD-HI type accounted for only $0.8 \% \quad(4 / 525) \quad$ and $0.4 \% \quad(2 / 525)$, respectively. Additionally, ADHD prevalence rated by teachers was higher than those rated by only parents. In terms of agreement percentage between parents/caregivers and teachers, the rate for ADHD-I type had the lowest agreement $(\mathrm{Kappa}=0.663)$ in both genders, whether that for ADHD$\mathrm{C}$ type achieved the closet agreement $(\mathrm{Kappa}=0.92)$. The prevalence of ADHD was significantly higher among boys $(6.5 \%)$ than girls $(2.1 \%)$, particularly at ADHD-C type (3.4\% in boys vs $1.3 \%$ in girls, respectively).

Table 3 illustrates that overall the risk of ADHD was higher in male pupils ( $\mathrm{aOR}=4.90,95 \%$ CI $1.51-15.85)$, those having a first-degree relative with ADHD ( $\mathrm{aOR}=85.2$, 95\% CI 1.66-4371.8), prenatal risk factors, typically in-utero exposure to maternal cigarette smoking ( $\mathrm{aOR}=4.78$, 95\% CI 1.31-17.44), and alcohol drinking $(\mathrm{aOR}=8.87,95 \%$ CI 2.29-34.42). No significant difference was found between the risk of ADHD and other children/ mothers' demographic characteristics (weight at birth, gestational age at birth, maternal age at childbirth, previous miscarriage) with a $\mathrm{p}$-value $>0.05$.

\section{Discussion}

In response to the increasing need to provide evidence on Vietnamese children's mental health, this cross-sectional study was carried out to investigate the rates of ADHD among 525 pupils aged 6 to 7 years in an urban city. Among the study sample, ADHD prevalence was reported to be at approximately $4.6 \%$, and ADHD combined type dominated with $3.4 \%$. Additionally, boy, family history of ADHD, presence of in-utero exposure to maternal cigarette smoking and alcohol drinking were identified to be associated with ADHD prevalence.

Generally, our result presented that the prevalence of ADHD in this study was slightly lower than the world population. ${ }^{14}$ Specifically, our study found a lower prevalence of $\mathrm{ADHD}(4.6 \%)$ as compared to findings from other countries, notably; $6.3 \%$ in Kenya, ${ }^{24} 5.91 \%$ in China, ${ }^{25}$ and $8.7 \%$ in the United States of America. ${ }^{19}$ However, the ADHD prevalence in our study population was similar to estimates in Saudi Arabia, ${ }^{26}$ and Oman population, ${ }^{27}$ and a recent meta-analysis with $3.4 \%$ (95\% CI 2.6-4.5) in children, ${ }^{28}$ in addition to significantly higher than that in Malaysia school-age children with only 1.61\% ADHD prevalence. $^{29}$ These variations can be explained by the diversity of measurement tools and geographical, cultural

Table 2 Rates of ADHD-Positively Screened Students by Parents and Teachers

\begin{tabular}{|c|c|c|c|c|c|c|c|}
\hline & \multirow[t]{2}{*}{$\mathbf{n}$} & Total $^{\mathbf{a}}$ & \multirow[t]{2}{*}{$\mathbf{n}$} & Parents' Rating & \multirow[t]{2}{*}{$\mathbf{n}$} & Teachers' Rating & \multirow[t]{2}{*}{$\boldsymbol{\kappa}$} \\
\hline & & $\%(95 \% \mathrm{Cl})$ & & $\%(95 \% \mathrm{Cl})$ & & $\%(95 \% \mathrm{Cl})$ & \\
\hline All $(n=525)$ & 24 & $4.6(2.8-6.4)$ & 26 & $4.9(3.1-6.8)$ & 31 & $5.9(3.9-7.9)$ & 0.87 \\
\hline ADHD-I, predominantly inattentive type & 4 & $0.8(0.02-1.5)$ & 5 & $1.0(0.01-2.2)$ & 7 & $1.3(0.3-2.3)$ & 0.66 \\
\hline ADHD-HI, predominantly hyperactivity/impulsivity type & 2 & $0.4(0.01-0.9)$ & 2 & $0.4(0.01-1.0)$ & 3 & $0.6(0.01-0.9)$ & 0.80 \\
\hline ADHD-C, Combined type & 18 & $3.4(1.8-4.9)$ & 19 & $3.6(2.6-7.7)$ & 21 & $3.8(2.4-5.9)$ & 0.92 \\
\hline Boys & 19 & $6.5(3.7-9.5)$ & 19 & $6.5(3.7-9.5)$ & 23 & $7.9(4.8-11.1)$ & 0.90 \\
\hline ADHD-I, predominantly inattentive type & 3 & $1.0(0.01-2.2)$ & 3 & $1.0(0.01-2.2)$ & 4 & $1.4(0.03-2.7)$ & 0.86 \\
\hline ADHD-HI, predominantly hyperactivity/impulsivity type & I & $0.3(0.01-1.0)$ & I & $0.3(0.01-1.0)$ & 1 & $0.3(0.01-1.0)$ & 1.00 \\
\hline ADHD-C, Combined type & 15 & $5.2(2.6-7.7)$ & 15 & $5.2(2.6-7.7)$ & 18 & $6.2(3.4-9.0)$ & 0.90 \\
\hline Girls & 5 & $2.1(0.3-4.0)$ & 7 & $3.0(0.8-5.2)$ & 8 & $3.4(1.1-5.7)$ & 0.88 \\
\hline ADHD-I, predominantly inattentive type & I & $0.4(0.01-1.2)$ & 2 & $0.8(0.01-2.0)$ & 3 & $1.2(0.01-2.7)$ & 0.80 \\
\hline ADHD-HI, predominantly hyperactivity/impulsivity type & 1 & $0.4(0.01-1.2)$ & I & $0.4(0.01-1.2)$ & 1 & $0.4(0.01-1.2)$ & 1.00 \\
\hline ADHD-C, Combined type & 3 & $1.3(0.0 \mathrm{I}-2.7)$ & 4 & $1.8(0.04-3.3)$ & 4 & $1.8(0.04-3.3)$ & 1.00 \\
\hline
\end{tabular}

Note: ${ }^{a}$ ADHD diagnose was confirmed only if both parent's and teacher's criteria were met following DSM-5 classification.

Abbreviations: ADHD-I, attention deficit hyperactivity disorder-predominantly inattentive type; ADHD-HI, attention deficit hyperactivity disorder-predominantly hyperactivity/impulsivity type; ADHD-C, attention deficit hyperactivity disorder-combined type; $\kappa$, Kappa coefficient of the interrater reliability. 
Table 3 Associated Factors of ADHD Symptoms via Bivariate and Multivariate Logistic Regression Models

\begin{tabular}{|c|c|c|c|c|c|c|}
\hline \multirow{2}{*}{ Variables } & \multirow{2}{*}{$\begin{array}{l}\text { Non-ADHD } \\
\text { n (\%) }\end{array}$} & \multirow{2}{*}{$\begin{array}{c}\text { ADHD } \\
\text { n (\%) }\end{array}$} & \multicolumn{2}{|l|}{ Bivariate } & \multicolumn{2}{|c|}{ Multivariate } \\
\hline & & & OR (95\% Cl) & $p$ & aOR $(95 \% \mathrm{CI})$ & $p$-value \\
\hline Sex & & & & 0.021 & & 0.020 \\
\hline Girl & $231(46.1)$ & $5(20.83)$ & 1.00 & & 1.00 & \\
\hline Boy & $270(53.9)$ & $19(79.17)$ & $3.25(1.2-8.84)$ & & $4.90(1.5|-| 5.85)$ & \\
\hline Weight at birth, grams & & & & 0.535 & & 0.530 \\
\hline$<2500$ & II (2.2) & $\mathrm{I}(4.2)$ & 1.00 & & 1.00 & \\
\hline$\geq 2500$ & $490(97.8)$ & $23(95.8)$ & $0.52(0.06-4.17)$ & & $0.35(0.03-3.78)$ & \\
\hline Gestational age at birth, weeks & & & & 0.004 & & 0.113 \\
\hline$\geq 37$ & $475(94.8)$ & $19(79.2)$ & 1.00 & & 1.00 & \\
\hline$<37$ & $26(5.2)$ & $5(20.8)$ & $4.62(|.60-| 3.3 \mid)$ & & $2.69(0.73-9.97)$ & \\
\hline First-degree relative history of ADHD & & & & 0.002 & & $<0.001$ \\
\hline No & $500(99.8)$ & $22(91.7)$ & 1.00 & & 1.00 & \\
\hline Yes & $\mathrm{I}(0.2)$ & $2(8.3)$ & $45.45(3.97-520.53)$ & & $85.2(1.66-4371.8)$ & \\
\hline Maternal age at childbirth, years & & & & 0.549 & & 0.840 \\
\hline$\geq 35$ & $100(20)$ & $6(25)$ & 1.00 & & 1.00 & \\
\hline$<35$ & $40 I(80)$ & $18(75)$ & $0.75(0.29-1.93)$ & & $0.93(0.30-2.86)$ & \\
\hline Previous Miscarriage & & & & 0.644 & & 0.266 \\
\hline No & $488(97.4)$ & $23(95.8)$ & 1.00 & & 1.00 & \\
\hline Yes & $13(2.6)$ & $\mathrm{I}(4.2)$ & $1.63(0.2-13.02)$ & & $0.11(0-5.39)$ & \\
\hline $\begin{array}{l}\text { Maternal smoking or exposure during } \\
\text { pregnancy }\end{array}$ & & & & 0.009 & & 0.004 \\
\hline No & $212(42.3)$ & $3(12.5)$ & 1.00 & & 1.00 & \\
\hline Yes & $289(57.7)$ & $21(87.5)$ & $5.13(1.51-17.44)$ & & $4.78(1.31-17.44)$ & \\
\hline Maternal alcohol drinking during pregnancy & & & & $<0.001$ & & $<0.001$ \\
\hline No & $489(97.6)$ & $18(75)$ & 1.00 & & 1.00 & \\
\hline Yes & $12(2.4)$ & $6(25)$ & $13.58(4.58-40.28)$ & & $8.87(2.29-34.42)$ & \\
\hline
\end{tabular}

Abbreviations: ADHA, attention deficit hyperactivity disorder; $\mathrm{OR}$, odds ratio; $\mathrm{Cl}$, confidence interval.

characteristics between countries. Differences in methodology may also explain the variations in the reported rate, typically the present study covered only children aged 6 to 7 years instead of pupils at all grades of primary school like in other studies. ${ }^{19,24-27,29}$ In Vietnam, few studies have analyzed data on ADHD rate, in which one earlier study carried out among primary school pupils in Mekong River Delta identified that an ADHD prevalence among primary schools (grades 1-5) with $7.7 \%$ was higher than our estimate. ${ }^{14}$ This disparity is assumed to be caused by the differences in study methodology and the improvement of mental health among pregnant women in Hue City, where the rate of maternal depression was found to be lower than in other cities in the North and South of Vietnam. ${ }^{30}$

Interestingly, similar to findings in previous studies, ${ }^{26,31}$ the present study suggested that those diagnosed with ADHD commonly have all symptoms of ADHD, including hyperactivity/impulsivity and inattention. Also, ADHD-C was the most common type among ADHD cases, followed by ADHD-I and ADHD-HI type. Significantly, the rates of ADHD scored pupils by teachers $(5.9 \%)$ were significantly higher than those scored by parents $(4.9 \%)$. Indeed, learning activities at school for pupils must pay more intensive attention for a specific time to solve, such as listening, writing, or calculating. Conversely, home activities are more open, flexible, require less attention, and are of long-term nature compared to highly restrictive and short termly engagement and structured thematic assessment at schools. As a result, some typical symptoms relating to ADHD might be much more easily recognized by teachers at school rather than parents or caregivers. This suggests that the ideal 
screening program and proper management for ADHD should be incorporated into the school health programs in collaboration with the parents at home to get the best result. Given that early detection and treatment for children with ADHD will reduce the potential problems in adulthood, ${ }^{12,16}$ however, in Vietnam, school health programs have not started to increase awareness and early diagnosis for ADHD symptom types.

The multivariate logistic regression models showed that ADHD was 4.90 times prevalent among boys higher than girls. This gender disparity was also proved in most of the previous studies in Vietnam and other populations. ${ }^{9,14,16,25,31,32}$ Our study also found a significant association between family history of ADHD in first-degree relatives with ADHD syndromes among pupils. This finding is in agreement with previous evidence, in which the genetic factor is the key contributor to ADHD syndromes among children. ${ }^{16}$ The present study has shown that ADHD was more likely to be encountered in children having a mother with a history of prenatal smoking 4.78 times. Also, children with prenatal alcohol exposure were 8.87 times more likely to have ADHD syndromes. In previous studies, it was estimated that the risk of ADHD was approximately two to four times higher among children with maternal cigarette smoking and alcohol drinking, ${ }^{17,19}$ combining with other environmental risk factors. ${ }^{1,15}$ Although it remains uncertain whether these associations are causal or mediated by unmeasured environmental or genetic confounders, ${ }^{16,33-35}$ in-utero exposure to cigarette smoke and alcohol has been demonstrated to lead to a range of neurodevelopmental disorders in both mothers and children. ${ }^{36-40}$ These findings have confirmed that there is a necessity for pregnant women to terminate exposures to tobacco smoke and alcoholic beverages. Recently, published data on smoking behavior in Vietnam have identified that active tobacco usage among women has stably remained lower than $2 \%,{ }^{41}$ but it is highlighted that passive smoking among pregnant women in 2019 was still at a relatively high level, typically $64.5 \%$ were second-hand exposed to tobacco in the last 30 days. ${ }^{42}$ Also, the latest study in Vietnam indicated that $13.4 \%$ of women had continued consuming alcohol when pregnancy. ${ }^{43}$ As a result, more adequate and prompt actions in limiting passive smoking and alcoholic beverages usage among pregnant women should be improved. In this study, we did not find any relationship between a history of preterm birth ( $<37$ weeks), mother's age, previous mother's prenatal miscarriage, which have been found to have some substantial impacts on ADHD among children in previous studies. ${ }^{20}$

Our study has some limitations that should be considered. Firstly, the relatively small sample size and number of pupils diagnosed with ADHD may affect the stability of percentages and odds ratio, making it difficult to precisely ascertain the real associations between the risk factors of ADHD and the prevalence of ADHD. Specifically, the association of family history with ADHD risk among our study sample should be particularly scrutinized due to very few cases that can explain this relationship (with only $2 / 24$ ADHD cases having a first-degree relative history of ADHD). Secondly, this was a cross-sectional study, so it is not possible to infer causal associations. Despite these limitations, our study provides the most current prevalence of ADHD and its associated risk factors among Vietnamese children in elementary (grade 1) schools. Conducting screening at this early stage has been proven beneficial in providing timely treatments with a good prognosis. Also, our study utilized the Vanderbilt Assessment Scales that is a validated and the most common tool for ADHD diagnosis. Notably, in addition to conducting faceto-face interviews to reduce the observational bias, our study carried out comprehensive evaluations rated by both teachers and caregivers. This type of evaluation is regarded to be mandatory for ADHD diagnosis.

\section{Conclusion}

Overall, the present study indicates that among the sampled pupils aged 6 to 7 years in Hue city in central Vietnam, the prevalence of ADHD is $4.6 \%$. Also, family history, alcohol drinking and tobacco use showed a strong association with ADHD. Evidence-based prevention strategies need to reduce exposure to potentially avoidable ADHD risk factors such as prenatal smoking and alcoholic drinking. Both elementary school teachers and parents should take up the role of identifying early signs and symptoms of ADHD among school-age children, particularly among pupils with a first-degree relative history of ADHD.

\section{Acknowledgments}

We thank all participating teachers working in Phu Cat, Thuan Loc, Ngu Binh, Truong An elementary school and the parents or guardians of pupils for responding to the questionnaire survey. 


\section{Disclosure}

The authors reported no conflicts of interest for this work and declared that the research was conducted in the absence of any commercial or financial relationships that could be construed as a potential conflict of interest.

\section{References}

1. Thapar A, Cooper M. Attention deficit hyperactivity disorder. Lancet. 2016;387(10024):1240-1250. doi:10.1016/S0140-6736(15)00238-X

2. Biederman J, Newcorn J, Sprich S. Comorbidity of attention deficit hyperactivity disorder with conduct, depressive, anxiety, and other disorders. Am J Psychiatry. 1991;148(5):564-577.

3. Matza LS, Paramore C, Prasad M. A review of the economic burden of ADHD. Cost Eff Resour Alloc. 2005;3(1):5. doi:10.1186/14787547-3-5

4. Baggio S, Fructuoso A, Guimaraes M, et al. Prevalence of attention deficit hyperactivity disorder in detention settings: a systematic review and meta-analysis. Front Psychiatry. 2018;9:331. doi:10.33 89/fpsyt.2018.00331

5. Fulton BD, Scheffler RM, Hinshaw SP. State variation in increased ADHD prevalence: links to NCLB school accountability and state medication laws. Psychiatr Serv. 2015;66(10):1074-1082. doi:10.11 76/appi.ps. 201400145

6. Brown RT, Freeman WS, Perrin JM, et al. Prevalence and assessment of attention-deficit/hyperactivity disorder in primary care settings. Pediatrics. 2001;107(3):E43. doi:10.1542/peds.107.3.e43

7. Wamulugwa J, Kakooza A, Kitaka SB, et al. Prevalence and associated factors of attention deficit hyperactivity disorder (ADHD) among Ugandan children; a cross-sectional study. Child Adolesc Psychiatry Ment Health. 2017;11:18. doi:10.1186/s13034-0170155-6

8. Bussing R, Fernandez M, Harwood M, et al. Parent and teacher SNAP-IV ratings of attention deficit hyperactivity disorder symptoms: psychometric properties and normative ratings from a school district sample. Assessment. 2008;15(3):317-328. doi:10.1177/ 1073191107313888

9. Russell AE, Ford T, Williams R, Russell G. The Association Between Socioeconomic Disadvantage and Attention Deficit/Hyperactivity Disorder (ADHD): a systematic review. Child Psychiatry Hum Dev. 2016;47(3):440-458. doi:10.1007/s10578-015-0578-3

10. Wolraich ML, Hagan JF Jr, Allan C, et al. Clinical practice guideline for the diagnosis, evaluation, and treatment of attention-deficit/hyperactivity disorder in children and adolescents. Pediatrics. 2019;144(4): e20192528. doi:10.1542/peds.2019-2528

11. Lahey BB, Pelham WE, Loney J, et al. Three-year predictive validity of DSM-IV attention deficit hyperactivity disorder in children diagnosed at 4-6 years of age. Am $J$ Psychiatry. 2004;161 (11):2014-2020. doi:10.1176/appi.ajp.161.11.2014

12. Wolraich M, Brown L, Brown RT, et al. ADHD: clinical practice guideline for the diagnosis, evaluation, and treatment of attention-deficit/hyperactivity disorder in children and adolescents. Pediatrics. 2011;128(5):1007-1022.

13. Government of Vietnam. Direction on strengthening health programs in schools 23/2006/CT-TTg; 2006. Available from: https://thuvienpha pluat.vn/van-ban/giao-duc/Chi-thi-23-2006-CT-TTg-tang-cuong-cong -tac-y-te-truong-hoc-13022.aspx. Accessed March 30, 2021.

14. Pham HD, Nguyen HB, Tran DT. Prevalence of ADHD in primary school children in Vinh Long, Vietnam. Pediatr Int. 2015;57 (5):856-859. doi:10.1111/ped.12656

15. Banerjee TD, Middleton F, Faraone SV. Environmental risk factors for attention-deficit hyperactivity disorder. Acta Paediatr. 2007;96 (9):1269-1274. doi:10.1111/j.1651-2227.2007.00430.x
16. Barnett R. Attention deficit hyperactivity disorder. Lancet. 2016;387 (10020):737. doi:10.1016/S0140-6736(16)00332-9

17. Mick E, Biederman J, Faraone SV, Sayer J, Kleinman S. Case-control study of attention-deficit hyperactivity disorder and maternal smoking, alcohol use, and drug use during pregnancy. J Am Acad Child Adolesc Psychiatry. 2002;41(4):378-385. doi:10.1097/00004583200204000-00009

18. Dahlin M, Nilsson C, Stotzer E, Runesh B. Mental distress, alcohol use and help-seeking among medical and business students: a cross-sectional comparative study. BMC Med Educ. 2011;11(1). doi:10.1186/1472-6920-11-92

19. Froehlich TE, Lanphear BP, Auinger P, et al. Association of tobacco and lead exposures with attention-deficit/hyperactivity disorder. Pediatrics. 2009;124(6):e1054-e1063. doi:10.1542/peds.2009-0738

20. Linnet KM, Wisborg K, Agerbo E, Secher NJ, Thomsen PH, Henriksen TB. Gestational age, birth weight, and the risk of hyperkinetic disorder. Arch Dis Child. 2006;91(8):655-660. doi:10.1136/ adc. 2005.088872

21. Obel C, Zhu JL, Olsen J, et al. The risk of attention deficit hyperactivity disorder in children exposed to maternal smoking during pregnancy - a re-examination using a sibling design. $J$ Child Psychol Psychiatry. 2016;57(4):532-537. doi:10.1111/jcpp.12478

22. American Academy of Pediatrics, National Initiative for Children's Healthcare Quality. NICHQ Vanderbilt assessment scales; 2002.

23. American Psychiatric Association. Diagnostic and Statistical Manual of Mental Disorders (DSM-5); 2013.

24. Wamithi S, Ochieng R, Njenga F, Akech S, Macharia WM. Crosssectional survey on prevalence of attention deficit hyperactivity disorder symptoms at a tertiary care health facility in Nairobi. Child Adolesc Psychiatry Ment Health. 2015;9(1):1. doi:10.1186/s13034-015-0033-z

25. Huang Y, Zheng S, Xu C, et al. Attention-deficit hyperactivity disorder in elementary school students in Shantou, China: prevalence, subtypes, and influencing factors. Neuropsychiatr Dis Treat. 2017;13:785-792. doi:10.2147/NDT.S126100

26. AlZaben FN, Sehlo MG, Alghamdi WA, et al. Prevalence of attention deficit hyperactivity disorder and comorbid psychiatric and behavioral problems among primary school students in western Saudi Arabia. Saudi Med J. 2018;39(1):52-58. doi:10.15537/smj.2018.1.21288

27. Al-Ghannami SS, Al-Adawi S, Ghebremeskel K, et al. Attention deficit hyperactivity disorder and parental factors in school children aged nine to ten years in Muscat, Oman. Oman Med J. 2018;33 (3):193-199. doi:10.5001/omj.2018.37

28. Polanczyk GV, Salum GA, Sugaya LS, Caye A, Rohde LA. Annual research review: a meta-analysis of the worldwide prevalence of mental disorders in children and adolescents. J Child Psychol Psychiatry. 2015;56(3):345-365. doi:10.1111/jcpp.12381

29. Gomez R, Hafetz N. DSM-IV ADHD: prevalence based on parent and teacher ratings of Malaysian primary school children. Asian J Psychiatr. 2011;4(1):41-44. doi:10.1016/j.ajp.2010.12.003

30. Murray L, Dunne MP, Van Vo T, Anh PNT, Khawaja NG, Cao TN. Postnatal depressive symptoms amongst women in Central Vietnam: a cross-sectional study investigating prevalence and associations with social, cultural and infant factors. BMC Pregnancy Childbirth. 2015;15(1). doi:10.1186/s12884-015-0662-5

31. Zorlu A, Unlu G, Cakaloz B, Zencir M, Buber A, Isildar Y. The Prevalence and Comorbidity Rates of ADHD Among School-Age Children in Turkey. J Atten Disord. 2020;24(9):1237-1245. doi:10. $1177 / 1087054715577991$

32. Lingineni RK, Biswas S, Ahmad N, Jackson BE, Bae S, Singh KP. Factors associated with attention deficit/hyperactivity disorder among US children: results from a national survey. BMC Pediatr. 2012;12 (1):50. doi:10.1186/1471-2431-12-50

33. Thapar A, Rice F, Hay D, et al. Prenatal smoking might not cause attention-deficit/hyperactivity disorder: evidence from a novel design. Biol Psychiatry. 2009;66(8):722-727. doi:10.1016/j.biopsych.2009. 05.032 
34. Schechter JC, Kollins SH. Prenatal smoke exposure and ADHD: advancing the field. Pediatrics. 2017;139(2):e20163481. doi:10.15 42/peds.2016-3481

35. Gustavson K, Ystrom E, Stoltenberg C, et al. Smoking in pregnancy and child ADHD. Pediatrics. 2017;139(2):e20162509. doi:10.1542/ peds.2016-2509

36. Raymond EG, Mills JL. Placental abruption. Maternal risk factors and associated fetal conditions. Acta Obstet Gynecol Scand. 1993;72 (8):633-639. doi:10.3109/00016349309021156

37. Marufu TC, Ahankari A, Coleman T, Lewis S. Maternal smoking and the risk of still birth: systematic review and meta-analysis. $B M C$ Public Health. 2015;15(1):239. doi:10.1186/s12889-015-1552-5

38. Williams JF, Smith VC. Fetal alcohol spectrum disorders. Pediatrics. 2015;136(5):e1395-e1406. doi:10.1542/peds.2015-3113

39. Skogerbø Å, Kesmodel US, Wimberley T, et al. The effects of low to moderate alcohol consumption and binge drinking in early pregnancy on executive function in 5-year-old children. BJOG. 2012;119 (10):1201-1210. doi:10.1111/j.1471-0528.2012.03397.x
40. Underbjerg M, Kesmodel US, Landrø NI, et al. The effects of low to moderate alcohol consumption and binge drinking in early pregnancy on selective and sustained attention in 5-year-old children. BJOG: 2012;119(10):1211-1221. doi:10.1111/j.1471-0528.2012.03396.x

41. Vietnam Ministry of Health HMU, General Statistics Office, et al. Global Adult Tobacco Survey (GATS) Vietnam 2015. Hanoi: Vietnam Ministry of Health; 2016.

42. Ngo CQ, Phan PT, Vu GV, et al. Prevalence and Sources of Second-Hand Smoking Exposure among Non-Smoking Pregnant Women in an Urban Setting of Vietnam. Int J Environ Res Public Health. 2019;16(24):5022. doi:10.3390/ijerph16245022

43. Nguyen CL, Nguyen PTH, Chu TK, et al. Cohort profile: maternal lifestyle and diet in relation to pregnancy, postpartum and infant health outcomes in Vietnam: a multicentre prospective cohort study. BMJ Open. 2017;7(9):e016794. doi:10.1136/bmjopen-2017-016794
Journal of Multidisciplinary Healthcare

\section{Publish your work in this journal}

The Journal of Multidisciplinary Healthcare is an international, peerreviewed open-access journal that aims to represent and publish research in healthcare areas delivered by practitioners of different disciplines. This includes studies and reviews conducted by multidisciplinary teams as well as research which evaluates the results or conduct of such teams or healthcare processes in general. The journal

\section{Dovepress}

covers a very wide range of areas and welcomes submissions from practitioners at all levels, from all over the world. The manuscript management system is completely online and includes a very quick and fair peer-review system. Visit http://www.dovepress.com/testimonials. php to read real quotes from published authors. 